\title{
Shielding blood donors from
}

\section{harm}

To the Editor: Eric Klug's letter in the June $S A M J^{[1]}$ is particularly topical, as haemovigilance programmes have extended to include donor health in recent years. Considerable attention has focused on the effects of regular blood donation on iron stores, and consequent risks of iron depletion and iron deficiency anaemia. There is little doubt that frequent blood donation may result in reduced iron stores. It is also important to note that haemoglobin $(\mathrm{Hb})$ levels may remain relatively normal in spite of reduced iron stores, although changes in the red cell indices may be helpful in suggesting iron deficiency. Females of childbearing age are most at risk of iron depletion due to menstruation, pregnancy, a lower body mass and lower oral iron intake.

There are two blood transfusion services in South Africa (SA). The South African National Blood Service (SANBS) covers the whole of SA with the exception of the Western Cape Province, which is serviced by the Western Province Blood Transfusion Service (WPBTS). The two services follow similar principles with regard to blood donor screening.

The SANBS screens $\mathrm{Hb}$ levels of all donors at each donation using the copper sulphate specific gravity method. If the donor's blood fails on this test, a HemoCue reading (a bedside $\mathrm{Hb}$ monitor) is done. The cut-off for all SANBS donors is an $\mathrm{Hb}$ level of $12.5 \mathrm{~g} / \mathrm{dl}$. If the donor fails the HemoCue test, they are given a letter of referral to their healthcare practitioner noting whether this is a first or repeat donation, and the number of donations. Dietary advice is offered to all donors, and in line with best practice, iron supplementation, where available, is given to repeat female donors of childbearing age. Female donors with $\mathrm{Hb}$ levels of $11.1-12.4 \mathrm{~g} / \mathrm{dl}$ and male donors with levels of $11.4-12.4 \mathrm{~g} / \mathrm{dl}$ are deferred from donating blood for 3 months. Female donors with an $\mathrm{Hb}$ level of $10.5-11.0 \mathrm{~g} / \mathrm{dl}$ are deferred for 6 months, and those with $\mathrm{Hb}$ levels $<10.5 \mathrm{~g} / \mathrm{dl}$ for 12 months. Male donors with an $\mathrm{Hb}$ level of $10.5-11.3 \mathrm{~g} / \mathrm{dl}$ are deferred from donating blood for 6 months and those with levels $<10.5 \mathrm{~g} / \mathrm{dl}$ for 12 months.

The WPBTS screens all donors at each donation using the HemoCue test. The Hb cut-off level for allowing donors to donate is $12.5 \mathrm{~g} / \mathrm{dl}$ for females and $13.5 \mathrm{~g} /$ $\mathrm{dl}$ for males. Regular donors failing to meet the cutoff levels have a sample taken for a full blood count (FBC). No matter what the results are, these donors later receive a letter with their FBC results, reflecting one of the following possibilities: $(i)$ failure of $\mathrm{Hb}$ screening test confirmed, but no evidence of anaemia 
or iron deficiency; (ii) failure of $\mathrm{Hb}$ screening test and evidence of anaemia or iron deficiency; or (iii) false failure of $\mathrm{Hb}$ screening test. Where indicated, donors are advised to see their own clinicians for further investigation and/or treatment. As with the SANBS, routine measurement of ferritin levels is not performed. The WPBTS recently introduced an oral iron replacement programme. A short course (30 tablets) of iron sulphate tablets is offered to those donors most at risk - currently female donors up to age 50 years who have donated two or more times in the preceding 12 months. This short course is intended only to replace the iron lost through donation, and not as a treatment for iron deficiency or iron deficiency anaemia. Accompanying information is supplied to explain the programme as well as to warn of side-effects. Research will be conducted over the next $2-3$ years in order to determine whether ferritin levels are maintained in those donors who receive iron replacement v. those who do not.

There are limited strategies aimed at reducing the risks of iron depletion in blood donors, each with its own challenges. The frequency of donation can be reduced to three or four donations per year. However, this would require a significant increase in the number of active blood donors to ensure that blood stocks are not compromised. Oral iron replacement programmes can be instituted; these are relatively inexpensive (particularly if iron sulphate is used), but the side-effects of oral iron are significant for some patients and compliance is limited - in a pilot study carried out by the WPBTS, compliance was measured at $70 \%$. Moreover, iron replacement programmes are not without risks, including the potential masking of more sinister causes of iron deficiency. Finally, ferritin levels (the most robust indicator of iron stores) can be measured. As there is no bedside ferritin test, screening would not be in real time. The costs of ferritin screening would need to be recovered (as both blood services are non-profit organisations based on financial models of cost recovery), and the price of blood would rise.
The blood transfusion services in South Africa benchmark at an international level to ensure blood safety by adopting guidelines put in place by the World Health Organization and the International Haemovigilance Network. Our haemovigilance programme, in addition to monitoring the safety of the transfusion chain, now includes donor vigilance and monitoring of international trends to minimise harm to donors. As such, the SANBS has embarked on a study of its donors in which an FBC, iron studies and ferritin levels will be done on a cohort of donors nationally; a sample of WPBTS donors will also be included. It is hoped that this will give a baseline for SA donors (rather than relying only on data from international studies). Using this analysis, going forward, interventions regarding frequency of donation, iron supplementation for certain donor groups and a costeffective plan for ferritin monitoring can be established.

Blood donors should be encouraged always to inform their treating clinicians that they are blood donors, and both services encourage this by way of a letter. In addition, both services will explore other avenues to inform blood donors of potential risks of donating, taking care not to deter donors and to ensure that the blood supply is not compromised.

\section{Charlotte Felicity Ingram}

South African National Blood Service, Johannesburg, South Africa dr.charlotte.ingram@gmail.com

\section{Gregory Ralph Martin Bellairs}

Western Province Blood Transfusion Service, Cape Town, South Africa

1. Klug E, Gebka M, Hellig F, Alison M, Townsend B, Naidoo V. Importance of shielding blood donors from harm. S Afr Med J 2014;104(6):389. [http://dx.doi.org/10.7196/SAMJ.8211]

S Afr Med J 2014;104(9):595-596. DOI:10.7196/SAMJ.8685 